\title{
Effects of Thermotherapy on the Quality of Life and Biochemical Parameters in Hemodialysis Patients with Uremic Pruritus
}

\author{
HAMED ZARE ${ }^{1}$, MAJIDEH HERAVI-KARIMOOI ${ }^{*}$, NAHID REJEH ${ }^{2}$, HAMID SHARIF NIA ${ }^{3}$ AND NADER NOORI MAJELAN ${ }^{4}$ \\ ${ }^{1}$ Genetic and Environmental Adventures Research Center, School of Abarkouh Paramedicine, Shahid sadoughi University of Medical \\ Sciences, Yazd, Iran \\ ${ }^{2}$ Elderly Care Research Center, Faculty of Nursing and Midwifery, Shahed University, Tehran, Iran \\ ${ }^{3}$ School of Nursing and Midwifery Amol, Mazandaran University of Medical Sciences, Sari, Iran \\ ${ }^{4}$ Medical School, Shahid Sadoughi University, Yazd, Iran \\ ${ }^{*}$ Corresponding author: Majideh Heravi-Karimooi, Department of Nursing, Shahed University, Opposite Holy Shrine of Imam Khomeini-Khalij \\ Fars Expressway, P. O. Box 18155/159, Tehran, IR Iran. Tel: +98-2151210, Fax: +98-2166418580, E-mail: heravi@shahed.ac.ir
}

\begin{abstract}
Introduction and objective: Uremic pruritus is a common symptom in patients under hemodialysis. The exact cause of uremic pruritus is not yet known. Although effective treatments are available, there is not still a commonly accepted treatment for this disorder. The present study was aimed at examining the effects of thermotherapy on the quality of life (QOL) and biochemical parameters in hemodialysis patients with uremic pruritus.

Patients and methods: In this experimental study, a total of 40 men under hemodialysis suffering from uremic pruritus were randomly selected and divided into an experimental group (thermotherapy) and a control group (no exposure to heat). The experimental group were exposed to far-infrared radiation (FIR) at $40{ }^{\circ} \mathrm{C}$ in 15 -minute sessions, three times a week, in total for 18 sessions. The Severity of Pruritus Scale (SPS), the Kidney Disease Quality of Life Instrument (KDQOL), and the ItchyQoL were completed by the participants before the start of intervention, one month after the start of intervention, and at the end of intervention. The data were analyzed using SPSS22.

Results: Significant differences were observed between the intervention and control groups in all the criteria for assessing uremic pruritus, including history of symptoms, daily activities, QOL, effects on sleep, emotional aspects, and severity of pruritus $(\mathrm{p}<0.001)$. In addition, significant improvements were found after the intervention in the criteria for assessing the QOL of the patients $(\mathrm{p}<0.001)$. Moreover, improvements in the calcium and phosphorus levels were observed in the intervention group in comparison with the control group.

Conclusion: Thermotherapy is effective in reducing the severity of pruritus and increasing the QOL of patents with this problem. Therefore, it can be used as a complementary method in treating patients with uremic pruritus who also experience a reduction in their QOL.

Keywords: Hemodialysis, Thermotherapy, Uremic pruritus, Quality of life, Biochemical parameters
\end{abstract}

\section{INTRODUCTION}

Hemodialysis patients experience multiple complications in all aspects of their lives as a result of the symptoms of the disease and the process of hemodialysis, and the qualitative standards of life can be considered rather unique in this group of patients. On the one hand, the problems and complications resulting from the disease lead to serious changes in the patients' diet, water intake, and rest-activity patterns. On the other hand, it has a costly and time-consuming process that limits the life of hemodialysis patients in both individual and social domains $(1,2)$.

Uremic pruritus is a common complication experienced by patients under hemodialysis that is due to renal failure and the subsequent hemodialysis. Uremic pruritus is observed in $25 \%$ of patients with chronic kidney disease (CKD) and $50-90 \%$ of people under hemodialysis at mild to severe levels [3]. It is observed with more severity in the last stages of renal failure, and can seriously affect the quality of life (QOL) of patients (3).

The QOL of patients in the last stages of renal failure is heavily dependent on dialysis adequacy and vascular access to have a high quality hemodialysis. As the disease progresses, the quality of hemodialysis is reduced; this leads to the sedimentation of combustible compounds in different areas of the patient's skin, therefore causing uremic pruritus (4).

Despite the high prevalence of uremic pruritus and its significant effects on the QOL of patients, it has not received enough attention in the research domain (5).It is difficult to control uremic pruritus due to limited number of instruments and treatment methods for this purpose. The research evidence shows that local therapies are frequently used to treat simple pruritus, but they are often effective only temporarily (1).

Today, most patients look for methods that can treat the symptoms of pruritus without the use of medications. Therefore, healthcare providers, especially nurses who are in direct contact with patients can use complementary methods to enhance the treatment of pruritus (6).

Among the complementary therapies for pruritus, thermotherapy using FIR that is out of the human vision has received more attention in recent years. It is important to note that when using thermotherapy, medication therapies and the routine care processes for the patients are continued and are not interfered by thermotherapy (7). FIR is a form of electromagnetic radiation with shorter wavelengths that is created using a lamp emitting the waves. It has been proved that FIR through thermotherapy has an important role in treating many vascular diseases, 
widening of blood vessels, and increasing the blood flow in the radiated area $(8)$.

In addition, thermotherapy using the repeated sauna treatment can improve the coronary arteries in the infarcted area (9). Thermotherapy using Waon therapy can improve vascular flow and increase endothelial function through increasing endothelial nitric oxide synthase (10). It has been shown that modern therapies, such as the use of thermotherapy to treat chronic fatigue syndrome (CFS) through creating a dry sauna using FIR can significantly reduce fatigue, pain, and low-grade fevers in patients; repeated thermotherapy has also sedative effects and leads to increased appetite and reduced complaints of mild depression in patients (11).

FIR effectively penetrates the subcutaneous tissues and reduces discomfort (8). It has been particularly maintained that thermotherapy using FIR can increase the blood flow and cell metabolism (12), reduce pain, lead to body tissue regeneration, increase oxygen delivery, and activate the immune response (13).

The process of controlling and reducing uremic pruritus in hemodialysis patients, has recently become focused on thermotherapy, and the research evidence has shown that thermotherapy using FIR significantly improves dialysis adequacy (14), therefore it can have positive effects on the QOL of patients under hemodialysis. Evaluation of the QOL of patients is useful in assessing the effectiveness of interventions as well as their cost-effectiveness (15). In addition to creating clinical and financial burdens, cardiovascular disease can threaten the health-related QOL of patients. Despite the increased interest in thermotherapy, no study in Iran has so far focused on its effects of uremic pruritus and the QOL of hemodialysis patients, Therefore, the goal of the present study is to examine the effects of thermotherapy on uremic pruritus and QOL among patients under hemodialysis.

\section{METHODS}

The present randomized, clinical trial was aimed at examining the effects of thermotherapy on the QOL and biochemical parameters of hemodialysis patients with uremic pruritus in the hemodialysis ward of Shahid Sadoughi hospital, Yazd, Iran. The study sample included a total of 40 patients who were randomly divided into an experimental and a control group. Sample size was determined as 40 (20 in each group) based on the article, titled "Effects of Thermotherapy on Uremic Pruritus and Biochemical Parameters in Patients under Hemodialysis" (16), using the $G^{*}$ Power software $(\alpha=0.05$; effect size $=$ 0.8; Power $=0.80$ ). In this experimental research, a Pretest-Midtest-Posttest design with a control group was used. Initially, a total of 81 hemodialysis patients with uremic pruritus were selected using a multistage random sampling method, of which 32 patients were excluded according to the inclusion criteria. The remaining 49 patents were randomly divided into an intervention $(n=24)$ and a control group $(n=25)$. Finally, 21 and 20 patients remained in the intervention and control groups, respectively. Severity of uremic pruritus and biochemical parameters were assessed at three time points of pretest, midtest, and posttest. Data were gathered using general instruments (a demographic questionnaire and a patient clinical scale) and specific instruments to collect laboratory data, including the Severity of Pruritus Scale (SPS), the Kidney Disease Quality of Life Instrument (KDQOL), and the ItchyQoL. The data were analyzed using SPSS22 (released 2007; SPSS for Windows, SPSS Inc., Chicago, IL, USA). The present clinical trial was registered in Iranian Registry of Clinical Trials under the number IRCT2017041333245N2 with the following number for ethics: IR.Shahed.REC.1395.195.

\section{RESULTS}

In the present study, a total of 40 patients were selected among male hemodialysis patients in the hemodialysis ward of Shahid Sadoughi hospital, Yazd, Iran. The mean age of participants in the control and experimental groups was 57.70 years and 55.65 years, respectively. The mean weight of participants in the control and experimental groups was $69.45 \mathrm{~kg}$ and $71.95 \mathrm{~kg}$, respectively. The mean height of participants in the control and experimental groups was $172.75 \mathrm{~cm}$ and $169.65 \mathrm{~cm}$, respectively. In terms of education level, in the control group, 13 participants had primary education, 6 had middle school education, and 1 had high school education; and in the experimental group, 10 participants had primary education, 5 had middle school education, and 5 had high school education or higher. In terms of marital status, in both groups, 1 participant was single and 19 were married. In terms of financial status, 17 participants in the control and 14 in the experimental group had an income lower than the standard level, and 3 participants in the control group and 6 in the experimental group had had an income in the standards level. In terms of employment, 4 and 16 participants in both groups were retired and unemployed, respectively. In terms of cigarette smoking, 5 participants in the control group and 3 participants in the experimental group smoked cigarettes. 10 participants in the control group and 7 participants in the experimental group used high blood pressure medications. The results show that both groups were similar in terms of demographic characteristics ( $P$ values ranging from 0.143 to 1 ).

Table 1 presents the means and standard deviations of the study criteria, including uremic pruritus, effects of pruritus on sleep, history of using antipruritic drugs, and effects of pruritus on everyday activities in both groups, assessed before intervention, one month after the start of intervention, and after the end of intervention, as well as comparisons between the two groups. Comparison of the two groups in uremic pruritus and its effects on sleep and everyday activities, showed a significant reduction in the experimental group, however, no significant difference was found between the two groups in history of using antipruritic drugs.

The means and standard deviations of the study criteria, assessed before the start of intervention, one month after the start of intervention, and after the end of intervention and comparisons between the two groups are presented in Table 2. 
Table 1. Means and standard deviations of uremic pruritus, effects of pruritus on sleep, history of taking antipruritic, and effects of pruritus on everyday activities in both groups, assessed before intervention, one month after the start of intervention, and after the end of intervention, as well as comparisons between the two groups.

\begin{tabular}{|c|c|c|c|c|c|c|c|}
\hline \multirow[b]{3}{*}{ Criteria } & \multicolumn{3}{|c|}{ Control group } & \multicolumn{3}{|c|}{ Experimental group } & \multirow{3}{*}{ Statistical test } \\
\hline & \multicolumn{3}{|c|}{ Time of assessment } & \multicolumn{3}{|c|}{ Time of assessment } & \\
\hline & $\begin{array}{l}\text { Before the } \\
\text { intervention }\end{array}$ & $\begin{array}{l}\text { One month after the start } \\
\text { of intervention }\end{array}$ & $\begin{array}{l}\text { After the end of } \\
\text { intervention }\end{array}$ & $\begin{array}{l}\text { Before the } \\
\text { intervention }\end{array}$ & $\begin{array}{l}\text { One month after the } \\
\text { start of intervention }\end{array}$ & $\begin{array}{l}\text { After the end of } \\
\text { intervention }\end{array}$ & \\
\hline Uremic pruritus & $10.6(2.5)$ & $11.2(2.35)$ & $10.8(1.9)$ & $10.55(2.1)$ & $9.3(2.03)$ & $8.2(2.2)$ & $\begin{array}{l}F(2)=9.7, \\
P<0.001 \\
E t a=0.203\end{array}$ \\
\hline $\begin{array}{l}\text { History of using antipruritic } \\
\text { drugs }\end{array}$ & $2.15(0.48)$ & $2.15(0.48)$ & $2.15(0.48)$ & $2.25(0.55)$ & $2.10(0.44)$ & $2.10(0.48)$ & \begin{tabular}{|l}
$F(2)=1.8$ \\
$P=0.169$ \\
$E t a=0.046$
\end{tabular} \\
\hline Effects of pruritus on sleep & 2.1 & 2.2 & 1.6 & 2.4 & 1.7 & 1.6 & $\begin{array}{l}F(1.6)=10.9, \\
P<0.001, \\
E t a=0.223\end{array}$ \\
\hline $\begin{array}{l}\text { Effects of pruritus on everyday } \\
\text { activities }\end{array}$ & $0.25(0.63)$ & $0.90(1.16)$ & $0.80(1.64)$ & $050(0.88)$ & $0.50(1.05)$ & $0.00(0.00)$ & $\begin{array}{l}F(2)=4.46, \\
P=0.015, \\
E t a=0.105\end{array}$ \\
\hline
\end{tabular}

Table 2. Means and standard deviations of the study criteria, assessed before the start of intervention, one month after the start of intervention, and after the end of intervention and comparisons between the two groups.

\begin{tabular}{|c|c|c|c|c|c|c|c|}
\hline \multirow[b]{3}{*}{ Criterion } & \multicolumn{3}{|c|}{ Control group } & \multicolumn{3}{|c|}{ Experimental group } & \multirow{3}{*}{ Statistical test } \\
\hline & \multicolumn{3}{|c|}{ Time of assessment } & \multicolumn{3}{|c|}{ Time of assessment } & \\
\hline & $\begin{array}{l}\text { Before the } \\
\text { intervention }\end{array}$ & $\begin{array}{l}\text { One month after the start } \\
\text { of intervention }\end{array}$ & $\begin{array}{l}\text { After the end of } \\
\text { intervention }\end{array}$ & $\begin{array}{l}\text { Before the } \\
\text { intervention }\end{array}$ & $\begin{array}{l}\text { One month after the } \\
\text { start of intervention }\end{array}$ & $\begin{array}{l}\text { After the end of } \\
\text { intervention }\end{array}$ & \\
\hline Effects of pruritus on QOL & $0.45(0.60)$ & $0.90(0.78)$ & $1.15(1.08)$ & $0.70(0.80)$ & $0.25(0.44)$ & $0.00(0.00)$ & $\begin{array}{l}F(2)=15.798, \\
P<0.001 \\
\text { Eta }=0.296\end{array}$ \\
\hline Description of emotional aspects & $3.9(2.06)$ & $4.4(2.13)$ & $4.6(1.81)$ & $4.6(1.56)$ & $2.6(1.26)$ & $2.4(1.14)$ & $\begin{array}{l}\mathrm{F}(1.26)=28.35, \\
\mathrm{P}<0.001, \\
\mathrm{Eta}=0.427\end{array}$ \\
\hline Current severity of pruritus & $4.8(1.36)$ & $5.1(1.63)$ & $5.5(1.39)$ & $5.15(1.53)$ & $3.2(1.00)$ & $2.2(1.11)$ & \begin{tabular}{|l}
$F(2)=34.85$ \\
$P<0.001$ \\
$E t a=0.478$
\end{tabular} \\
\hline Severity of pruritus at the worst level & $7.3(1.38)$ & $7.3(1.34)$ & $7.6(1.27)$ & $7.7(1.33)$ & $6.6(1.18)$ & $5.5(1.27)$ & $\begin{array}{l}F(2)=77437, \\
P<0.001 \\
E t a=0.203498\end{array}$ \\
\hline Severity of pruritus at the lowest level & $3.25(0.55)$ & $3.35(0.81)$ & $3.20(0.76)$ & $3.35(0.58)$ & $2.8(1.00)$ & $1.4(1.27)$ & $\begin{array}{l}F(1.41)=19.42, \\
P<0.001, \\
E t a=0.337\end{array}$ \\
\hline Quality of physical health & $30.95(2.35)$ & $46.30(1.52)$ & $46.5(2.68)$ & $33.45(4.94)$ & $41.9(7.2)$ & $41.1(6.7)$ & $\begin{array}{l}F(1.66)=41.99, \\
P<0.001, \\
E t a=0.525\end{array}$ \\
\hline Quality of feelings and emotions & $89.85(3.67)$ & $71.75(3.76)$ & 72.85 (5.31) & $90.15(8.19)$ & $72.35(9.10)$ & $67.9(9.5)$ & $\begin{array}{l}F(1.66)=41.99, \\
P<0.001, \\
E t a=0.525\end{array}$ \\
\hline Improvement of clinical records & $34.85(4.24)$ & $34.90(2.46)$ & $35.95(2.66)$ & $39.45(7.25)$ & $34.55(8.04)$ & $31.55(7.29)$ & $\begin{array}{l}F(1.70)=29.48, \\
P<0.001, \\
E t a=0.437\end{array}$ \\
\hline Limitations in everyday activities & $24.00(4.05)$ & $21.45(2.21)$ & $23.20(2.74)$ & $26.45(6.22)$ & $25.45(6.73)$ & $25.20(6.13)$ & $\begin{array}{l}F(1.64)=3.10 \\
P=0.003 \\
\text { Eta }=0.076\end{array}$ \\
\hline Sexual activity & $1.70(0.470)$ & $1.30(0.470)$ & $1.55(0.510)$ & $1.10(0.307)$ & $1.15(0.366)$ & $1.70(0.470)$ & \begin{tabular}{|l}
$\mathrm{F}(2)=7.09$ \\
$\mathrm{P}<0.001$ \\
$\mathrm{Eta}=0.157$
\end{tabular} \\
\hline Sexual disorders & $8.4(1.23)$ & $8.7(0.86)$ & $8.1(1.33)$ & $8.4(1.95)$ & $7.8(1.96)$ & $7.6(2.41)$ & $\begin{array}{l}F(2)=1.74, \\
P=0.182, \\
E t a=0.044\end{array}$ \\
\hline Sleep quality & $8.9(1.94)$ & $7.8(1.39)$ & $8.8(1.36)$ & $8.8(1.79)$ & $8.2(1.85)$ & $8.45(2.45)$ & $\begin{array}{l}F(2)=0.902, \\
P=0.410, \\
\text { Eta }=0.023\end{array}$ \\
\hline General and family relationships & $5.50(1.05)$ & $6.30(0.97)$ & $5.4(0.75)$ & $6.6(2.13)$ & $5.85(1.56)$ & $5.75(1.55)$ & $\begin{array}{l}F(1.72)=6.31 \\
P=0.005, \\
E t a=0.143\end{array}$ \\
\hline Job quality & $3.00(0.72)$ & $3.50(0.51)$ & $3.50(0.51)$ & $3.2(1.01)$ & $3.05(0.94)$ & $3.25(0.91)$ & \begin{tabular}{|l}
$F(2)=6.12$, \\
$P=0.003$ \\
$E t a=0.139$
\end{tabular} \\
\hline Satisfaction with the received care & $8.50(1.10)$ & $8.55(0.94)$ & $8.15(0.810)$ & $8.60(2.21)$ & $8.20(1.93)$ & $8.40(1.87)$ & $\begin{array}{l}F(1.66)=1.92 \\
P=0.161 \\
E t a=0.048\end{array}$ \\
\hline Quality of pruritus symptoms & $15.50(2.80)$ & $15.60(2.68)$ & $14.85(2.00)$ & $17.65(3.55)$ & $16.35(2.77)$ & $10.80(2.94)$ & $\begin{array}{l}F(2)=16.76 \\
P<0.001 \\
E t a=0.306\end{array}$ \\
\hline Quality of everyday activities & 35.25 (4.39) & 34.45 (4.22) & 33.20 (3.65) & $38.40(6.72)$ & $36.30(6.89)$ & $43.25(6.74)$ & $\begin{array}{l}F(2)=802, \\
P=0.452 \\
E t a=0.021\end{array}$ \\
\hline $\begin{array}{l}\text { Quality of feelings and emotions (the } \\
\text { ItchyQoL) }\end{array}$ & $33.05(4.17)$ & $34.10(5.03)$ & $34.5(4.94)$ & $36.65(6.73)$ & $34.25(6.83)$ & $30.30(6.96)$ & $\begin{array}{l}F(2)=10.6, \\
P<0.001, \\
E t a=0.218\end{array}$ \\
\hline QOL of patients with pruritus & $83.80(5.54)$ & $84.15(6.93)$ & $82.20(5.52)$ & $92.70(12.25)$ & $86.90(12.57)$ & $75.35(12.65)$ & $\begin{array}{l}F(2)=13.215 \\
P<0.001 \\
E t a=0.258\end{array}$ \\
\hline
\end{tabular}


Based on the Comparison between the two groups at the three stages of before, during, and after the intervention, the assumption of sphericity was confirmed using the Mauchly's test. The descriptive statistics showed that the means and standard deviations of most criteria at the three stages of assessment were significantly different between the two groups. However, according to the descriptive statistics, the means and standard deviations of sexual disorders, sleep quality, satisfaction with the received care, and quality of everyday activities at the three stages of assessment were not significantly different between the two groups.

Table 3. Levels of biochemical parameters in the experimental and control groups before the start of intervention, one month after the start of intervention, and after the end of intervention, and the results of comparisons between the two groups.

\begin{tabular}{|c|c|}
\hline Biochemical parameter & Time of assessment \\
\hline \multirow[t]{3}{*}{ Calcium } & Before \\
\hline & During \\
\hline & After \\
\hline \multirow[t]{3}{*}{ Phosphorus } & Before \\
\hline & During \\
\hline & After \\
\hline \multirow[t]{3}{*}{ Albumin } & Before \\
\hline & During \\
\hline & After \\
\hline \multirow[t]{3}{*}{ Alkaline phosphatase } & Before \\
\hline & During \\
\hline & After \\
\hline \multirow[t]{3}{*}{ Urea } & Before \\
\hline & During \\
\hline & After \\
\hline \multirow[t]{2}{*}{ Hematocrit } & Before \\
\hline & After \\
\hline \multirow[t]{2}{*}{ Hemoglobin } & Before \\
\hline & After \\
\hline \multirow[t]{2}{*}{ Parathyroid hormone (PTH) } & Before \\
\hline & After \\
\hline \multirow[t]{2}{*}{ Calcium $\times$ phosphorus ratio } & Before \\
\hline & \begin{tabular}{|l|} 
During \\
After
\end{tabular} \\
\hline
\end{tabular}

In the experimental group, all the biochemical parameters changed after the intervention in comparison with the preintervention period.

\section{DISCUSSION}

The goal of the present study was to examine the effects of thermotherapy using FIR on uremic pruritus and QOL among male hemodialysis patients in the hemodialysis ward of Shahid Sadoughi hospital, Yazd, Iran in 2018. The study findings are consistent with some of the previous findings on this topic. In a study by et al. (2009), the effects of thermotherapy using FIR were compared with those of a non-thermal therapy on uremic pruritus and biochemical parameters in patients under hemodialysis. In this randomized, double-blind trial, 41 hemodialysis patients with uremic pruritus were divided into a thermotherapy and a control group. The thermotherapy group received FIR at $40{ }^{\circ} \mathrm{C}$ for 15 minutes, once a day, twice a week, in a total of 18 sessions. While, the control group received routine treatment programs, including acupuncture. The results indicated significant improvements in the severity of uremic pruritus in both groups, while a relatively large reduction in uremic pruritus was observed in the thermotherapy group. In addition, a significant decrease was found in the calcium $x$ phosphorus ratio in the serum of patients in the thermotherapy group. Finally, the authors concluded that FIR through reducing the serum calcium $\times$ phosphorus ratio as one the most important causes of pruritus had led to a relative improvement in the symptoms of the patients. But,

\begin{tabular}{|l|l|l|}
\hline Control group & Experimental group & P-value \\
\hline 10.02 & 9.78 & 0.08 \\
\hline 10.09 & 10.00 & 0.07 \\
\hline 9.87 & 9.54 & 0.02 \\
\hline 5.50 & 5.06 & .39 \\
\hline 5.01 & 4.35 & 0.11 \\
\hline 5.01 & 4.70 & 0.38 \\
\hline 3.97 & 3.72 & 0.03 \\
\hline 3.98 & 3.69 & 0.04 \\
\hline 3.98 & 3.78 & 0.09 \\
\hline 90.76 & 81.40 & 0.26 \\
\hline 89.71 & 77.40 & 0.17 \\
\hline 93.24 & 80.15 & 0.38 \\
\hline 1.39 & 1.54 & 0.20 \\
\hline 1.45 & 1.64 & 0.13 \\
\hline 1.46 & 1.75 & 0.02 \\
\hline 32.49 & 30.45 & 0.19 \\
\hline 32.11 & 29.34 & 0.03 \\
\hline 11.01 & 10.22 & 0.14 \\
\hline 10.98 & 9.91 & 0.01 \\
\hline 322.4 & 154.33 & 0.02 \\
\hline 431.57 & 240.64 & 0.16 \\
\hline 55.51 & 49.59 & 0.35 \\
\hline 51.19 & 43.24 & 0.09 \\
\hline 49.38 & 44.42 & 0.26 \\
\hline
\end{tabular}

they emphasized that more studies with larger sample sizes and using long-term interventions would be needed to confirm their results.

Yaghoubi et al. (2012), Mohammadpoor et al. (2016), and Young et al. (2010), found the effectiveness of FIR on pain reduction (30), reduction in systolic and diastolic blood pressure, and a sudden increase in the tensile strength of the skin within one or two weeks, respectively. But, the results of a study by Tabatabaei et al. (2009) showed a reduction in the severity of pain and an increase in the clinical range of motion in the thermotherapy group; however, they found no significant differences between the two groups. The results of studies by Elizabeth and et al. indicated the effectiveness of non-pharmacological therapies in reducing uremic pruritus; this emphasize that non-pharmacological therapies can be effective for treating hemodialysis patients suffering from uremic pruritus, and that the use of complementary therapies to treat this problem is recommended.

Some of the previous studies have led to consistent results with those of the present study in terms of $\mathrm{QOL}$ et al. (2012), examined the relationship between severe pruritus, psychological complications, and QOL in 20 patients with eczema, 20 patients with psoriasis, 20 patients with urticaria, 12 patients with congenital pruritus, 11 patients with pruritus caused by renal failure, and 20 patients with cardiovascular disease, using a researcher-made checklist assessing age, gender, diagnosis, severity of symptoms, sleep quality, depression, anxiety, non-specific somatic 
symptoms and QOL under pruritus. They found a significant relationship between pruritus and QOL in patients with urticaria. In the patients with severe pruritus, quality of sleep had been influenced more than depression symptoms. In addition, the effects of anxiety were more severe than those of non-specific somatic complications. Finally, the authors concluded that the multidimensional nature of pruritus led to depression, anxiety, and reduced QOL; this is in line with the previous reports (8).

conducted a study, titled "Thermotherapy in Hemodialysis Patients: Effects of Far Infrared Radiation on Dialysis Adequacy among Hemodialysis Patients." Et al. (2011), They found significant improvements in the group receiving FIR $(p<0.05)$ compared to the control group. They concluded that thermotherapy significantly improved dialysis adequacy, and emphasized the use of FIR in treating patients under hemodialysis.

In their experimental study, Young et al. (2010), found no significant difference in the tensile strength between the FIR and control groups. However, they found a sudden increase in tensile strength in the FIR group during one and two weeks $(p=0.033)$. In addition, tensile strength during two weeks was significantly higher in the FIR group compared to the control group $(p=0.049)$. This results of this study indicates that in short-term, the FIR can have a reducing effect in the generation of inflammatory changes and increase of the tensile strength of the skin.

conducted an experimental study, titled "Effects of Repeated Thermotherapy on the QOL of Patients with Diabetes Mellitus Type 2"(2010), and examined the effects of thermotherapy on the QOL of patients with diabetes mellitus type 2. Their intervention included 20-minute sessions of therapeutic FIR sauna, three times a week, during a three months period. In this study, the Short FormHealth Survey version 2 (SF-36v2) and the visual analogue scale (VAS) were completed by the participants. Preintervention assessments of the parameters were conducted 1 week before the start of intervention, and postintervention assessments were conducted within 1 to 3 days following the last session of the sauna. The results according to the data from the SF-36v2, indicated improvements in physical health, general health, and social functioning of the intervention group. In addition, analysis of the data from the VAS indicated improvements in stress and fatigue. It was finally concluded that the FIR sauna can improve the QOL of people with diabetes type 2 .

\section{CONCLUSION}

Thermotherapy is significantly related to uremic pruritus and QOL, and the patients who received thermotherapy experienced relative improvements in their uremic pruritus symptoms and QOL. In addition, examination of biochemical parameters indicated a significant reduction in the calcium $\times$ phosphorus ratio. Therefore, thermotherapy could be regarded as a complementary therapy to treat uremic pruritus and increase QOL in patents under hemodialysis.

\section{REFERENCES}

1. Akça NK, Taşcl S. Acupressure and Transcutaneous Electrical Acupoint Stimulation for Improving Uremic Pruritus: A Randomized, Controlled Trial. Alternative Therapies in Health \& Medicine. 2016;22(3).

2. Sa'ed HZ, Daraghmeh DN, Mezyed DO, Khdeir RL, Sawafta $\mathrm{MN}$, Ayaseh NA, et al. Factors affecting quality of life in patients on haemodialysis: a cross-sectional study from Palestine. BMC nephrology. 2016;17(1):44.

3. Mettang $\mathrm{T}$, Kremer AE. Uremic pruritus. Kidney international. 2015;87(4):685-91.

4. Chen C-F, Yang W-C, Lin C-C. An update of the effect of far infrared therapy on arteriovenous access in end-stage renal disease patients. The journal of vascular access. 2016;17(4):293-8.

5. Attia EA, Hassan AA. Uremic pruritus pathogenesis, revisited. Arab journal of nephrology and transplantation. 2014;7(2):91-6.

6. Cameron ID, Murray GR, Gillespie LD, Robertson MC, Hill $K D$, Cumming RG, et al. Interventions for preventing falls in older people in nursing care facilities and hospitals. The Cochrane database of systematic reviews. 2010(1):Cd005465.

7. Tabatabaei H, TABATABAEI A, MOOSAVI J. Effect of sauna on pain of rheumatoid arthritis patients. 2009.

8. Lin C-C, Chang C-F, Lai M-Y, Chen T-W, Lee P-C, Yang WC. Far-infrared therapy: a novel treatment to improve access blood flow and unassisted patency of arteriovenous fistula in hemodialysis patients. Journal of the American Society of Nephrology. 2007;18(3):985-92.

9. Sobajima M, Nozawa T, Shida T, Ohori T, Suzuki T, Matsuki $A$, et al. Repeated sauna therapy attenuates ventricular remodeling after myocardial infarction in rats by increasing coronary vascularity of noninfarcted myocardium. American Journal of Physiology-Heart and Circulatory Physiology. 2011;301(2):H548-H54.

10. Miyata M, Tei C. Waon therapy for cardiovascular disease. Circulation journal. 2010:1002100612-.

11. Masuda A, Munemoto T, Tei C. A new treatment: thermal therapy for chronic fatigue syndrome. Nihon rinsho Japanese journal of clinical medicine. 2007;65(6):1093-8.

12. Yu SY, Chiu JH, Yang SD, Hsu YC, Lui WY, Wu CW. Biological effect of far-infrared therapy on increasing skin microcirculation in rats. Photodermatology, photoimmunology \& photomedicine. 2006;22(2):78-86.

13. Hattori T, Kokura S, Okuda T, Okayama T, Takagi T, Handa $\mathrm{O}$, et al. Antitumor effect of whole body hyperthermia with agalactosylceramide in a subcutaneous tumor model of colon cancer. International Journal of Hyperthermia. 2007;23(7):591-8.

14. Lin C-h, Lee L-S, Su L-H, Huang T-C, Liu C-F. Thermal Therapy in Dialysis Patients - A Randomized Trial2011. 839$51 \mathrm{p}$.

15. Nekouei ZK, Yousefy A, Manshaee Q. The Effect of Cognitive-Behavioral Therapy on the Improvement of Cardiac Patients' Life Quality. Iranian Journal of Medical Education. 2010;10(2).

16. Brunicardi FC, Schwartz SI. Schwartzs principles of surgery: McGraw-Hill; 2005. 